\title{
Variation in Mouse Basolateral Amygdala Volume is Associated With Differences in Stress Reactivity and Fear Learning
}

\author{
Rebecca J Yang', Khyobeni Mozhui ${ }^{2}$, Rose-Marie Karlsson', Heather A Cameron ${ }^{3}$, Robert W Williams ${ }^{2}$ and \\ Andrew Holmes*, I \\ 'Section on Behavioral Science and Genetics, Laboratory for Integrative Neuroscience, National Institute on Alcohol Abuse and Alcoholism, NIH, \\ Rockville, MD, USA; '2Department of Anatomy and Neurobiology, University of Tennessee Health Science Center, Memphis, TN, USA; ${ }^{3}$ Unit on \\ Neuroplasticity, Mood and Anxiety Disorders Program, National Institute of Mental Health, NIH, Bethesda, MD, USA
}

\begin{abstract}
A wealth of research identifies the amygdala as a key brain region mediating negative affect, and implicates amygdala dysfunction in the pathophysiology of anxiety disorders. Although there is a strong genetic component to anxiety disorders such as posttraumatic stress disorder (PTSD) there remains debate about whether abnormalities in amygdala function predispose to these disorders. In the present study, groups of $\mathrm{C} 57 \mathrm{BL} / 6 \times \mathrm{DBA} / 2(\mathrm{~B} \times \mathrm{D})$ recombinant inbred strains of mice were selected for differences in volume of the basolateral amygdala complex (BLA). Strains with relatively small, medium, or large BLA volumes were compared for Pavlovian fear learning and memory, anxiety-related behaviors, depression-related behavior, and glucocorticoid responses to stress. Strains with relatively small BLA exhibited stronger conditioned fear responses to both auditory tone and contextual stimuli, as compared to groups with larger BLA. The small BLA group also showed significantly greater corticosterone responses to stress than the larger BLA groups. BLA volume did not predict clear differences in measures of anxiety-like behavior or depression-related behavior, other than greater locomotor inhibition to novelty in strains with smaller BLA. Neither striatal, hippocampal nor cerebellar volumes correlated significantly with any behavioral measure. The present data demonstrate a phenotype of enhanced fear conditioning and exaggerated glucocorticoid responses to stress associated with small BLA volume. This profile is reminiscent of the increased fear processing and stress reactivity that is associated with amygdala excitability and reduced amygdala volume in humans carrying loss of function polymorphisms in the serotonin transporter and monoamine oxidase A genes. Our study provides a unique example of how natural variation in amygdala volume associates with specific fear- and stress-related phenotypes in rodents, and further supports the role of amygdala dysfunction in anxiety disorders such as PTSD. Neuropsychopharmacology (2008) 33, 2595-2604; doi: I0.1038/sj.npp. I 30 I665; published online 9 January 2008
\end{abstract}

Keywords: amygdala; gene; fear; memory; PTSD; stress

\section{INTRODUCTION}

The past decade has seen great advances in understanding how genetically driven individual differences in the anatomy and function of specific brain regions confer risk for a variety of neuropsychiatric diseases (Caspi and Moffitt, 2006; Hariri et al, 2006). This literature is based upon the assumption that associations between genes, neural function, and clinical end points are causative in nature. However, associations between clinical symptoms and measures of neural activation are invariably made a posteriori: that is after the phenotype is observed. By contrast, there has been little demonstration that variation in a brain region

\footnotetext{
*Correspondence: Dr A Holmes, Section on Behavioral Science and Genetics, Laboratory for Integrative Neuroscience, National Institute on Alcohol Abuse and Alcoholism, 5625 Fishers Lane Room 2N09, Rockville, MD 20852-94 I I, USA, Tel: + | 301402 35 |9, Fax: + | 30 | 480 1952, E-mail: holmesan@mail.nih.gov

Received I5 October 2007; revised 5 November 2007; accepted 7 November 2007
}

of interest can successfully predict, a priori, the likely prevalence of a clinical or behavioral trait.

A pertinent case in point is posttraumatic stress disorder (PTSD). There is a significant genetic component to risk for PTSD (Kendler, 2001), as well as neurological abnormalities in unaffected probands that are suggestive of antecedent genetic or familial risk factors (Gurvits et al, 2006). Functional neuroimaging studies have identified hyperactivity of the amygdala as a neural correlate for the clinical symptoms seen in PTSD (Rauch et al, 2006; Shin et al, 2006). In addition, some but not all structural imaging and postmortem studies have found a trend for smaller left amygdala volume in patients with the disorder (Bremner $\mathrm{et} \mathrm{al}$, 1997; Bonne et al, 2001; De Bellis et al, 2001, 2002; FennemaNotestine et al, 2002; Lindauer et al, 2004; Wignall et al, 2004; Karl et al, 2006). Taken together, these findings suggest that amygdala dysfunction may predispose individuals to PTSD and other stress-related disorders. However, while there are data showing that smaller hippocampal volume can precede the development of PTSD (Gilbertson et al, 2002), the 
hypothesis that variation in amygdala anatomy can lead to PTSD has not been directly tested.

A major role for the amygdala in PTSD is consistent with a large corpus of data from animal models demonstrating amygdala mediation of a spectrum of behavioral and mnemonic functions that include, but are not limited to, the regulation of emotion and negative affect (Davis and Whalen, 2001; Robbins and Everitt, 2002; Fanselow and Poulos, 2005; Phelps and LeDoux, 2005). Ablation of specific subnuclei of the rat amygdala produces alterations in certain fear-, anxiety-, and stress-related behaviors. Specifically, the basolateral amygdala complex (BLA) appears necessary for the formation and/or expression of associative fear memories. This has led to a model in which the lateral nucleus within BLA serves as a convergence site for sensory and aversive information that is relayed either directly or via the basal nucleus to the major output center of the amygdala, the central nucleus (CeA), to drive fearrelated behaviors (Fanselow and LeDoux, 1999; Maren and Quirk, 2004). Thus, rodents receiving pre-training lesions of the lateral, but not basal, nucleus fail to form fear memories (Goosens and Maren, 2001; Nader et al, 2001; Koo et al, 2004), while post-training lesions of the basal nucleus prevent the expression of fear memory but not the ability to acquire new memories (Anglada-Figueroa and Quirk, 2005). These findings provide clear evidence that the BLA is necessary for certain forms of learned fear behavior. They do not, however, address the issue of whether natural variation in amygdala anatomy and function is sufficient to predict differences in these behaviors.

In the present study, we sought to address this issue by utilizing a genetically defined panel of C57BL/ $6 \times \mathrm{DBA} / 2$ (BXD) recombinant inbred strains that we have recently shown to exhibit up to twofold variation in BLA volume in large sample of 37 RI lines (Mozhui et al, 2007). BXD RI mice are inbred strains derived from C57BL/6 and DBA/2 (Taylor, 1978; Chesler et al, 2003) that have been used to identify chromosomal loci underlying fear- and anxiety-related phenotypes (Caldarone et al, 1997; Owen et al, 1997; Wehner et al, 1997; Valentinuzzi et al, 1998), as well as volume and cell number variation in various brain regions (Neumann et al, 1993; Airey et al, 2001, 2002; Lu et al, 2001; Rosen and Williams, 2001; Williams et al, 2001; Seecharan et al, 2003). We selected 17 BXD RI lines and assigned them to subgroups with relatively small, medium, and large BLA volume. Our objective was to test whether a priori categorization of mice according to BLA volume differences within a natural range was sufficient to predict differences in fear-, anxiety-, and stress-related phenotypes. The results obtained provide some of the strongest evidence to date that genetically driven variation in amygdala volume is sufficient to predict the magnitude of fear- and stress-related phenotypes.

\section{MATERIALS AND METHODS}

\section{Histology and BXD RI Strain Selection}

Histological analysis of the BXD RI lines was performed previously at the Department of Anatomy and Neurobiology, University of Tennessee Health Science Center, and is described in detail by Mozhui et al (2007). Briefly,
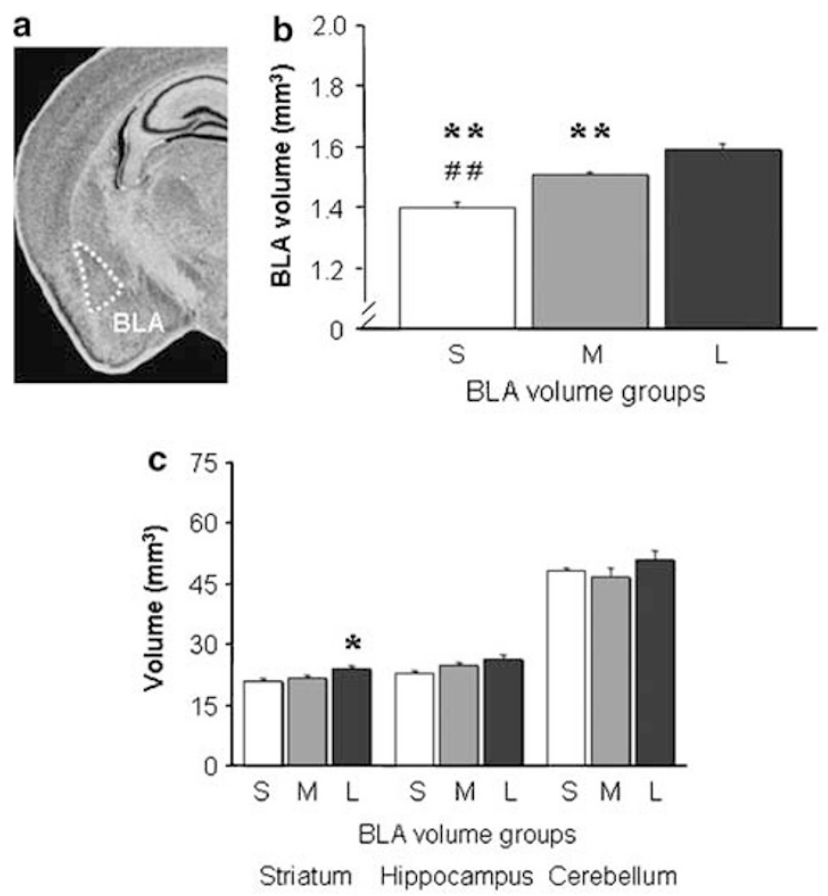

Figure I Basolateral amygdala (BLA) volume differences in a panel of BXD RI lines. (a) Neuroanatomical definition of the BLA complex. (b) BLA volume differences in mice selected for relatively small (S), medium (M), and large (L) BLA. (c) Dorsal striatal, total hippocampal, and total cerebellar volume differences in mice selected for BLA volume differences $(n=24-38$

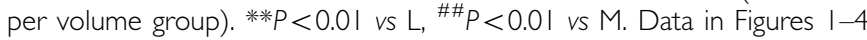
are means \pm SEM.

the BLA complex was defined as the portion between the external capsule and the amygdalar capsule, as described by Swanson and Petrovich (1998). This includes the lateral and basolateral, but not basomedial, nuclei (Figure 1a). Images from bilateral $30 \mu \mathrm{m}$ thick serial sections were captured from a Zeiss light microscope to a computer and the BLA was manually traced to determine cross-sectional area $\left(\mathrm{mm}^{2}\right)$ along the entire rostrocaudal thickness of the BLA ( 6-9 sections for each brain). Volume was calculated by multiplying the interval thickness between serial sections (which was $300 \mu \mathrm{m}$ ) and correcting for volumetric shrinkage caused by the histological process ((measured values/ total brain volume) $\times$ expected brain volume for given brain weight). Post-processing total brain volume was determined by the point-counting method described by Williams (2000). These data can be viewed at an anatomical database at www.genenetwork.org.

\section{Selection of BXD RI Lines and Assignment to BLA Volume Groups}

In an earlier study, we conducted a comprehensive analysis of $35 \mathrm{BXD}$ RI lines (plus the C57BL/6J and DBA/2J parental lines) for BLA volume (Mozhui et al, 2007). This revealed up to twofold variation in BLA volume across this panel of RI lines. In the current study we obtained a subset of this larger panel. We selected lines on the basis of a desire to obtain a range of relatively small, medium, and large BLA volumes; but this was limited by the availability of lines from a single commercial vendor (The Jackson Laboratory, Bar Harbor, ME), which was necessary to avoid a potentially 
confounding source of variability (ie supplier). Of the 15 BXD RI lines (plus the C57BL/6J and DBA/2J parental lines) obtained, we cross-referenced with the dataset (Mozhui et al, 2007) to assign an approximately equal number of lines to 'small,' 'medium,' and 'large' groups. This resulted in five lines in the small group (BXD13, BXD21, BXD28, BXD38, and BXD39), seven lines in the medium group (BXD8, BXD11, BXD12, BXD23, BXD31, BXD34, and DBA/ $2 J)$, and five lines in the large group (BXD16, BXD19, BXD22, BXD32, and C57BL/6J). Next, we took the BLA volume data for each line (an average of $n=4-8$ mice per line) from the dataset (Mozhui et al, 2007) and calculated the mean average and within-group variance of BLA volume within each of our three volume groupings. Volume differences between the subgroups were then analyzed using one-way analysis of variance (ANOVA) followed by Newman-Keuls post hoc analysis. This showed that the subgroups differed significantly from one another (main effect of volume group: $\mathrm{F}_{2,14}=18.58$, post hoc comparisons: all $P<0.01)$. For depiction of mean differences and withingroup variance as measured by standard error, see Figure $1 \mathrm{~b}$. For depiction of mean differences and within-group variance as measured by standard deviation, see Supplementary Figure 1a. For depiction of mean differences and individual line values, see Supplementary Figure 1b.

To determine whether BLA volume differences in our groups generalized to other brain regions, we obtained the volume values for dorsal striatum (caudate putamen), total hippocampus, and total cerebellum in each of the RI lines we tested from www.genenetwork.org. These data were originally described in the following sources: for dorsal striatum, Rosen and Williams (2001) and Lu et al, 2001, for hippocampus, including dentate gyrus, excluding subiculum, Peirce et al (2003); and for cerebellum, Airey et al (2001). For neuroanatomical definitions of these regions see Supplementary Figure 2. One-way ANOVA and post hoc tests showed that the subset of RI lines we designated as the large BLA groups also had significantly greater striatal volume than the group designated as the small BLA group (main effect of group: $\mathrm{F}_{2,14}=3.78, P<0.05$, post hoc comparison: $P<0.05$; Figure $1 \mathrm{c}$ ). ANOVA showed that the BLA subgroups did not significantly differ in either total hippocampal or cerebellar volume (Figure 1c).

\section{Animal Husbandry and Behavioral Phenotyping}

Mice were bred at The Jackson Laboratory and transported to the NIH at $\sim 8$ weeks of age and housed 1-4 per cage in same-strain groupings in a temperature- and humiditycontrolled vivarium under a $12 \mathrm{~h}$ light-dark cycle (lights on 0600 hours). There were a total of 190 male mice at the start of the study, with at least $n=8-12 /$ RI line except for BXD28 $(n=5)$. This resulted in a total of 47 mice in the small BLA group, 82 in the medium BLA group, and 61 in the large BLA group. Behavioral testing was conducted during the light phase between 0900 and 1700 hours. Given evidence of qualitative differences between rodent tests for anxiety-like behavior (Holmes et al, 2003), three separate tests were employed. Mice were tested on a battery of tests in the following order with the putatively more stressful assays at the end of the sequence and at least 1 week between tests: exploratory and anxiety-like behavior (novel open-field, elevated plus-maze, light-dark exploration tests), Pavlovian fear conditioning, depression-related behavior (forced swim test, FST), hot plate (as a control for pain perception in fear conditioning), and glucocorticoid responses to stress (corticosterone levels following swim stress). All experimental procedures were performed in accordance with the National Institutes of Health Guide for Care and Use of Laboratory Animals and were approved by the local Animal Care and Use Committee.

\section{Pavlovian Fear Conditioning}

Pavlovian fear conditioning (Kim and Fanselow, 1992) was conducted in a chamber with transparent walls and a metal rod floor based on methods described previously (Wellman et al, 2007). To provide a distinctive olfactory environment, the chamber was cleaned between subjects with a $79.5 \%$ water $19.5 \%$ ethanol $/ 1 \%$ vanilla extract solution. After an initial $120 \mathrm{~s}$ acclimation period, the mouse received three pairings (60-120 s interval after each pairing) between the conditioned stimulus (CS; $30 \mathrm{~s}, 80 \mathrm{~dB}, 3 \mathrm{kHz}$ tone) and the unconditioned stimulus (US; $2 \mathrm{~s}, 0.6 \mathrm{~mA}$ scrambled footshock), in which the US was presented during the last $2 \mathrm{~s}$ of the CS. The presentation of stimuli was controlled by a San Diego Instruments (San Diego Instruments, San Diego, CA) or Med Associates fear conditioning system (Med Associates, Burlington, VT).

After $24 \mathrm{~h}$, expression of the fear memory for the CS was tested in a novel context, in a different room from training. The novel context had black/white checkered walls and a solid Plexiglas, opaque floor. This chamber was cleaned between subjects with a $50 \%$ ethanol $/ 50 \%$ water solution. After an initial $180 \mathrm{~s}$ acclimation period, the CS was continuously presented for $180 \mathrm{~s}$.

After $24 \mathrm{~h}$, expression of the fear memory for the conditioned context was tested in the same room as conditioning by placing the mouse in the training chamber for $5 \mathrm{~min}$. Freezing was defined as absence of any visible movement except that required for respiration, and was scored at $5 \mathrm{~s}$ intervals by an observer who was blind to BXD line. The number of observations scored as freezing was converted to a percentage ((number of freezing observations/total number of observations $) \times 100)$ for analysis.

The hot plate test was conducted as a control for group differences in pain perception (Boyce-Rustay and Holmes, 2006). The apparatus was a flat plate (Columbus Instruments, Columbus, $\mathrm{OH}$ ) heated to $55^{\circ} \mathrm{C}$ on which the mouse was placed. The latency to show a hind paw shake or lick was timed by an observer, with a maximum response latency of $30 \mathrm{~s}$.

\section{Depression-Related Behavior and Glucocorticoid Responses to Stress}

The FST was conducted as previously described (Porsolt et al, 1978; Hefner and Holmes, 2007). The apparatus was a transparent Plexiglas cylinder $(25 \mathrm{~cm}$ high, $20 \mathrm{~cm}$ diameter $)$ filled halfway with water $\left(24 \pm 1^{\circ} \mathrm{C}\right)$ into which the mouse was gently lowered for a $10 \mathrm{~min}$ trial. The presence/absence of immobility (cessation of limb movements except minor involuntary movements of the hind limbs) was manually observed using an instantaneous sampling technique every 
$5 \mathrm{~s}$ during the last $8 \mathrm{~min}$ and expressed as a percentage of total observations. The result was converted to a percentage ((number of immobility observations/total number of observations) $\times 100$ ) for analysis.

Glucocorticoid responses to stress were measured after a 4-week rest period following the FST described above. The mouse was subjected to a $10 \mathrm{~min}$ forced swim stress trial and then returned to the home cage. After $30 \mathrm{~min}$, mice were killed via rapid cervical dislocation and decapitation to collect trunk blood. Nonstressed controls were killed within $30 \mathrm{~s}$ of removal from the home cage. To minimize disturbance of nonstressed controls, all mice were individually housed $24 \mathrm{~h}$ prior to killing. Blood samples were centrifuged at 13000 r.p.m. for 30 s. Serum was extracted and assayed for total corticosterone (bound and free) using the Coat-a-Count RIA TKRC1 kit (limit of detection $5.7 \mathrm{ng} /$ ml; Diagnostic Products Corp, Los Angeles) as previously described (Boyce-Rustay et al, 2007).

\section{Anxiety-Related Behavior}

The novel open-field test was conducted as previously described (Wiedholz et al, 2007). The apparatus was a square arena $(39 \mathrm{~cm} \times 39 \mathrm{~cm} \times 35 \mathrm{~cm})$ with opaque white Plexiglas walls and floor that was evenly illuminated to $\sim 20$ lux. The mouse was placed in a corner and allowed to freely explore for $30 \mathrm{~min}$. Distance traveled, time spent moving, time spent in the $(20 \mathrm{~cm} \times 20 \mathrm{~cm})$ center, and entries into the center were measured using the Ethovision videotracking system (Noldus Information Technology Inc., Leesburg, VA). The apparatus was cleaned with $70 \% \mathrm{EtOH}(\mathrm{v} / \mathrm{v})$ and dried between subjects.

The elevated plus-maze test was conducted as previously described (Handley and Mithani, 1984; Boyce-Rustay and Holmes, 2006). The apparatus consisted of two open arms $(30 \mathrm{~cm} \times 5 \mathrm{~cm} ; 55$ lux $)$ and two closed arms $(30 \mathrm{~cm} \times$ $5 \mathrm{~cm} \times 15 \mathrm{~cm} ; 5$ lux) extending from a $5 \mathrm{~cm} \times 5 \mathrm{~cm}$ central area and elevated $20 \mathrm{~cm}$ from the ground (San Diego Instruments). The walls were made from black $A B S$ plastic and the floor from white ABS plastic. A $0.5 \mathrm{~cm}$ raised lip around the perimeter of the open arms prevented mice from falling off the maze. The mouse was placed in the center facing an open arm and allowed to explore the apparatus for $5 \mathrm{~min}$. Time spent in the open arms, and entries into the open and closed arms were measured by the Ethovision videotracking system (Noldus Information Technology Inc.). The apparatus was cleaned with $70 \% \mathrm{EtOH}(\mathrm{v} / \mathrm{v})$ and dried between subjects.

The light-dark exploration test was conducted as previously described (Crawley, 1981; Boyce-Rustay and Holmes, 2006). The apparatus consisted of two compartments (each $17 \mathrm{~cm} \times 13 \mathrm{~cm} \times 13 \mathrm{~cm}$ ), one with white Plexiglas walls and clear Plexiglas floor (40 lux) ('light' compartment) and the other with black Plexiglas walls and clear Plexiglas floor (0 lux) ('dark' compartment), which were connected by a partition at floor level with a small opening $(5 \mathrm{~cm})(\mathrm{Med}$ Associates, Georgia, VT, Model ENV-3013). The mouse was placed into the dark compartment facing away from the aperture and allowed to explore the apparatus for $10 \mathrm{~min}$. Time spent and full-body transitions into the light compartment, and total full-body transitions between the light and dark compartments were measured by photocells connected to Med Associates software. The apparatus was cleaned with $70 \% \mathrm{EtOH}(\mathrm{v} / \mathrm{v})$ and dried between subjects.

\section{Statistics}

BLA group effects were analyzed using ANOVA and Newman-Keuls post hoc tests where appropriate. One mouse was an extreme outlier ( $>5$ standard deviations from the mean) for preconditioning freezing and was excluded from the study. Genetic correlations were performed (treating each of the 17 strains as an individual data point) between BLA, dorsal striatal, total hippocampal, and cerebellar volume, and behavioral and neuroendocrine measures using Spearman's test. The threshold for statistical significance was set at $P<0.05$. DATA ACCESSAll phenotype data sets that are part of this paper are available at www.genenetwork.org in the mouse BXD phenotypes database. Twenty-four records can be retrieved by entering the term ${ }^{3}$ yang $\mathrm{rj}^{2}$ in the ALL field. Alternatively, individual traits can be returned using GeneNetwork trait ID numbers such as ${ }^{3} 10873^{2}$ for baseline plasma corticosterone titers. Data include strain means and s.e.m values, but not data for individual animals.

\section{RESULTS}

\section{Pavlovian Fear Conditioning}

There was no significant difference between BLA groups for percent freezing during the (2-min) preconditioning or (2-min) postconditioning periods (Figure 2a). BLA groups significantly differed in percent freezing to the CS $\left(\mathrm{F}_{2,158}=\right.$ 7.74, $P<0.01)$ and context $\left(\mathrm{F}_{2,159}=5.37, P<0.01\right)$. The small BLA group froze more in response to the CS (Figure $2 \mathrm{~b}$ ) and to the context (Figure 2c) than the medium or large groups. There was a significant genetic correlation between freezing to CS and volume of BLA, but not striatum, hippocampus, or cerebellum (Table 1).

There were no group differences in the hot plate test for nociception (mean \pm SEM latency to respond: small $=$ $6.42 \pm 0.47 \mathrm{~s}$, medium $=7.39 \pm 0.48 \mathrm{~s}$ and large $=6.14 \pm 0.37 \mathrm{~s}$ ).

\section{Depression-Related Behavior and Glucocorticoid Responses to Stress}

There was no effect of BLA group on percent immobility in the FST (Figure 3a). Corticosterone levels were affected by stress in a BLA group-dependent manner (stress $\times$ group interaction: $\left.F_{2,41}=3.41, P<0.05\right)$. While there were no group differences in corticosterone in nonstressed mice, corticosterone levels following stress were significantly greater in the small BLA group than the medium or large groups (Figure 3b). There was a significant baseline correlation between nonstressed corticosterone and striatal, but not BLA, hippocampus, or cerebellar, volume (Table 1).

\section{Tests for Anxiety-Related Behavior}

There was a significant effect of BLA group on distance traveled $\left(\mathrm{F}_{2,186}=8.21, P<0.01\right)$, but not percent time in the center in the novel open-field test. The small BLA volume group traveled less than the medium or large BLA 

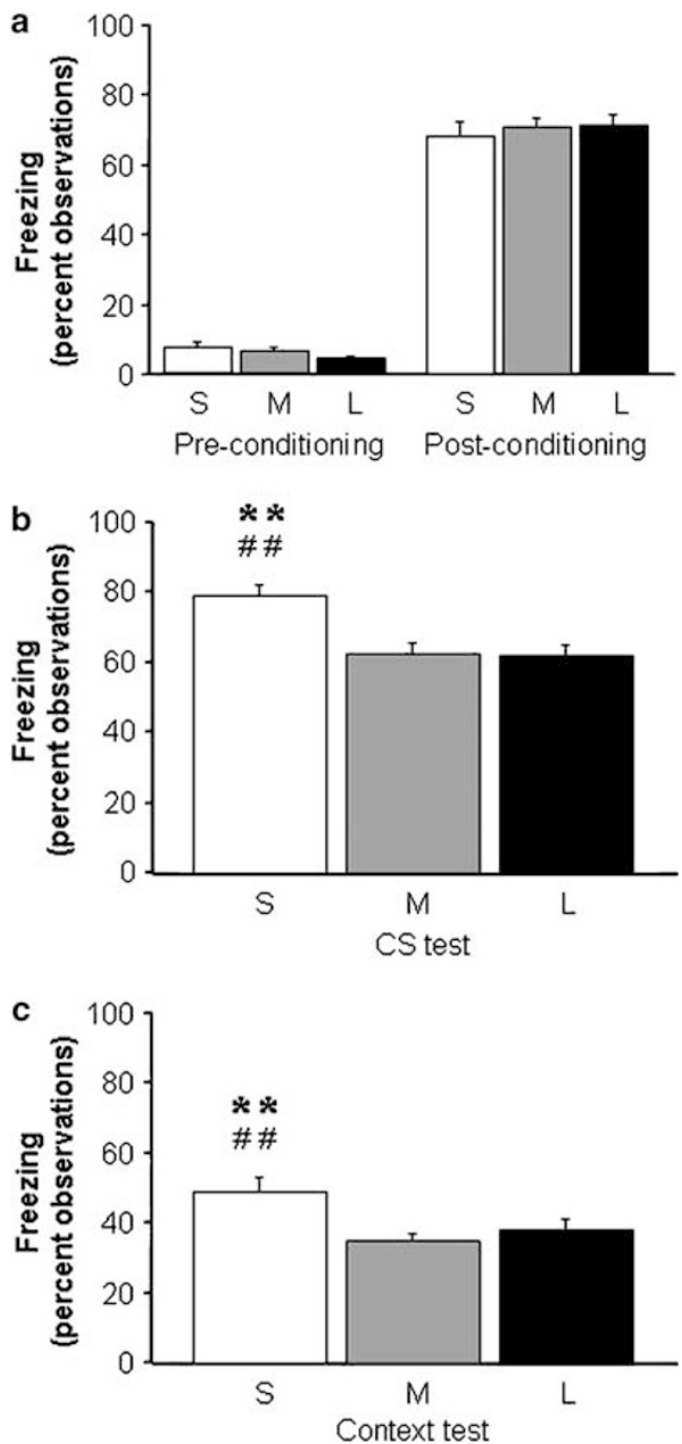

Figure 2 Pavlovian fear conditioning in mice differing in basolateral amygdala (BLA) volume. There were no differences in freezing during the preconditioning or immediate postconditioning periods between mice with relatively small (S), medium (M), or large $(L)$ BLA volume. The small BLA group froze more than medium or large BLA groups during exposure to the conditioned stimulus (CS) and conditioned context $(n=35-75$ per volume group). ${ }^{*} * P<0.0$ I, ${ }^{*} P<0.05$ vs $\mathrm{L},{ }^{\# \#} P<0.0$ I vs $\mathrm{M}$.

volume groups (Figure 4a), while percent time in the center was no different between groups (Figure $4 \mathrm{~b}$ ). There was a significant genetic correlation between distance traveled and volume of BLA, but not striatum, hippocampus or cerebellum (Table 1).

There was a significant effect of BLA group on total $\left(\mathrm{F}_{2,183}=4.24, P<0.05\right)$ and closed arm entries $\left(\mathrm{F}_{2,183}=\right.$ $6.93, P<0.01)$ and percent time in the center square $\left(\mathrm{F}_{2,183}=8.28, P<0.01\right)$, but not percent open arm time or open arm entries in the elevated plus-maze. The medium and small BLA groups spent less time in the center square (Figure 4c) and made fewer total and closed arm entries (Figure 4d) than the large BLA volume group. There was a significant genetic correlation between percent center time and volume of BLA, but not striatum, hippocampus, or cerebellum (Table 1).
Table I Genetic Correlations Between Volume of BLA, Striatum, Hippocampus, or Cerebellum and Fear, Anxiety- and StressRelated Behaviors

Volume

BLA Striatum Hippocampus Cerebellum

\begin{tabular}{|c|c|c|c|c|}
\hline \multicolumn{5}{|l|}{ Pavlovian fear conditioning } \\
\hline $\begin{array}{l}\text { Preconditioning } \\
\text { freezing }\end{array}$ & -0.23 & -0.04 & -0.33 & 0.52 \\
\hline $\begin{array}{l}\text { Postconditioning } \\
\text { freezing }\end{array}$ & -0.03 & -0.05 & -0.17 & 0.20 \\
\hline $\begin{array}{l}\text { Freezing to } \\
\text { conditioned cue }\end{array}$ & $-0.50 *$ & -0.21 & -0.42 & -0.03 \\
\hline $\begin{array}{l}\text { Freezing to } \\
\text { conditioned context }\end{array}$ & -0.29 & 0.06 & -0.06 & 0.21 \\
\hline \multicolumn{5}{|l|}{ Forced swim test } \\
\hline Immobility & -0.13 & -0.30 & 0.02 & -0.25 \\
\hline \multicolumn{5}{|l|}{ Corticosterone } \\
\hline Baseline & -0.10 & $-0.42 *$ & -0.24 & - \\
\hline Poststress & -0.49 & 0.18 & 0.18 & 0.37 \\
\hline \multicolumn{5}{|l|}{ Novel open field } \\
\hline Distance traveled & $0.50 *$ & 0.04 & 0.30 & -0.41 \\
\hline Center time & 0.34 & 0.18 & 0.39 & -0.12 \\
\hline \multicolumn{5}{|l|}{ Elevated plus-maze } \\
\hline Time in open arms & -0.04 & -0.47 & -0.31 & -0.12 \\
\hline Time in center square & $0.65 *$ & 0.43 & 0.16 & -0.05 \\
\hline Total arm entries & 0.38 & 0.21 & -0.02 & -0.07 \\
\hline Open arm entries & 0.02 & -0.35 & -0.06 & -0.23 \\
\hline Closed arm entries & 0.43 & 0.42 & 0.06 & 0.22 \\
\hline \multicolumn{5}{|l|}{ Dark-light exploration } \\
\hline Time in light & 0.37 & -0.12 & 0.27 & -0.24 \\
\hline Light-dark transitions & 0.34 & -0.20 & 0.11 & -0.24 \\
\hline
\end{tabular}

Abbreviation: BLA, basolateral amygdala complex. $* P<0.05$.

There was a significant effect of BLA group on percent time in the light compartment $\left(\mathrm{F}_{2,175}=4.14, P<0.05\right)$ and light-dark transitions $\left(\mathrm{F}_{2,175}=13.16, P<0.01\right)$ in the lightdark exploration test. The medium and small BLA groups spent less time in the light compartment (Figure 4e) and made fewer light-dark transitions (Figure $4 \mathrm{f}$ ) than the large BLA volume group, while the medium group made fewer transitions than the large group. Neither measure significantly correlated with volume of BLA, striatum, hippocampus, or cerebellum (Table 1).

\section{DISCUSSION}

The major finding of the present study was that variation in volume of the BLA complex in a panel of BXD RI inbred strains 

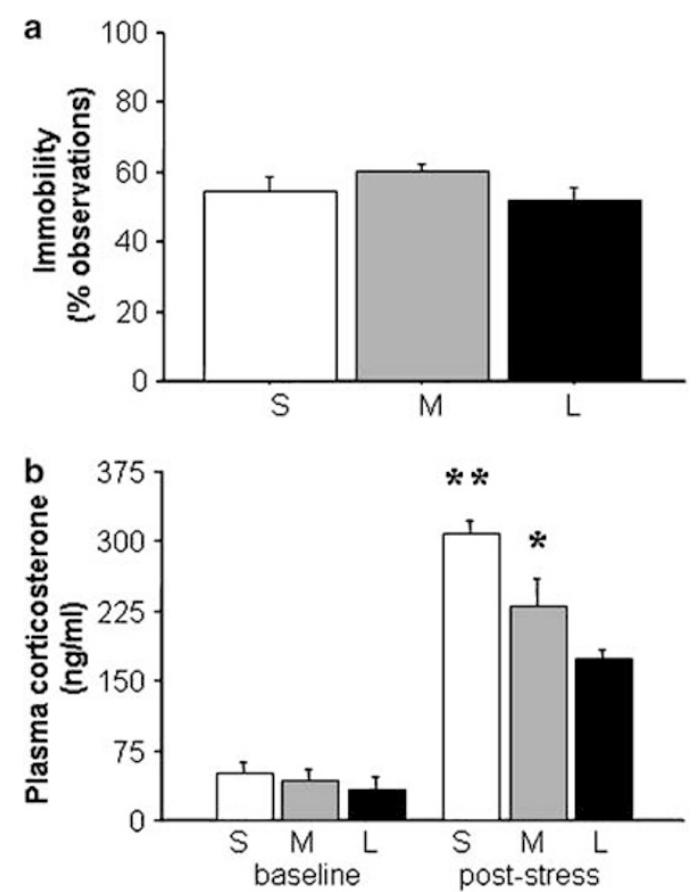

Figure 3 Depression-related behavior and glucocorticoid responses to stress in mice differing in basolateral amygdala (BLA) volume. BLA volume was not associated with differences in percent immobility in the forced swim test (a) ( $n=25-49$ per volume group). Mice with relatively small (S) BLA showed normal baseline corticosterone, but higher corticosterone responses to swim stress than medium (M) or large (L) BLA groups (b) ( $n=5-$ I I per volume group per stress condition). $* * P<0.0$ I, *P $<0.05$ vs L.

was associated with differences in specific measures of mouse fear-, anxiety-, depression-, and stress-related phenotypes.

There is compelling evidence that the BLA is necessary for the formation and expression of associative fear memories, as typically evidenced by the effects of lesions on the type of Pavlovian fear conditioning task employed in our study (Davis and Whalen, 2001; Fanselow and Poulos, 2005; Phelps and LeDoux, 2005). The present findings reinforce and extend this literature by showing that mice with naturally occurring variation in BLA volume exhibit significant differences in fear conditioning. BXD RI strains selected for BLA volumes that were relatively small showed significantly greater levels of conditioned freezing than strains with a larger BLA. There were no differences in levels of freezing immediately prior to or immediately after conditioning, demonstrating that differences between BLA groups in the recall/expression of fear memory were not due to differences in unconditioned freezing or in capacity to express short-term fear memory. Moreover, pain perception measured in the hot plate test did not differ between the groups, excluding variation in pain perception as a confounding influence.

Differences in fear expression between volume BLA groups were found both for conditioned fear to discrete (auditory cue) and compound (context) stimuli, which is consistent with the ability of BLA lesions (Goosens and Maren, 2001) and gene knockout-induced gross disruption of BLA (Lin et al, 2005) to impair both forms of associative fear memory. Interestingly however, there was a significant genetic correlation between BLA volume-varying BXD lines and cued, but not contextual, conditioned fear. A relatively

greater correlation for cued conditioning is in agreement with evidence from lesion studies demonstrating the importance of the BLA for cued relative to contextual fear conditioning, the latter involving greater recruitment of additional structures, notably the hippocampus (Maren and Quirk, 2004). These data also concur with gene-mapping studies in BXD RIs indicating that cued and contextual conditioning are under partly dissociable genetic control (Owen et al, 1997; Wehner et al, 1997). Finally, the fact that we were able to detect two correlating phenotypic traits (BLA volume and fear memory) across two laboratories (University of Tennessee, NIH) speaks both to the strength and replicability of the underlying genetic component (Wahlsten et al, 2006).

BLA volume-related variation in fear conditioning was dissociated from differences in anxiety-like behavior. The small BLA volume group showed less locomotor exploration in the novel open-field and elevated plus-maze than the larger BLA groups, but there were no differences in the principal measures of anxiety-like behavior (open-field center time, elevated plus-maze open arm exploration). In a third test of anxiety-like behavior, the light-dark exploration test, the small and medium BLA groups spent less time in the light compartment and made fewer light-dark intercompartment transitions than the large BLA group. Different mouse tests for anxiety likely measure different forms of behavior controlled by distinct genetic factors (Turri et al, 1999; Holmes et al, 2003; Kliethermes and Crabbe, 2006) and it is possible that the profile of the small and medium BLA groups in the light-dark exploration test reflects a high anxiety-like phenotype that is not seen in the other tests. Taken together however, the differences between BLA volume groups on the anxiety-related assays (particularly the open-field and light-dark exploration tests) were marginal and are most parsimoniously interpreted as modest locomotor inhibition in response to novelty rather than a clear high anxiety-like phenotype in mice with smaller BLA volumes. Indeed, the absence of anxiety-related differences would be consistent with the lack of effects of BLA lesions or temporary inactivation on anxiety-like behaviors in rats tested under the standard task conditions used in the current study (Decker et al, 1995; Moller et al, 1997; Herry et al, 2007; Moreira et al, 2007).

To our knowledge, there has been little investigation of the role of BLA in rodent depression-related behaviors; with one study finding no effect of BLA lesions in the rat FST for depression-related behavior (Shimazoe et al, 1988). The present data found no link between variation in BLA volume and immobility in the mouse FST. By contrast, BLA groups differed markedly in their glucocorticoid responses to swim stress. Thus, while baseline levels of corticosterone were no different between the groups, corticosterone levels following swim stress were significantly greater in small BLA mice than in the larger BLA groups.

A pathway from the main output nucleus of the amygdala, the CeA, to the paraventricular nucleus of the hypothalamus (Swanson and Petrovich, 1998) is thought to modulate hypothalamic-pituitary-adrenal (HPA) axis responses to stress (reviewed in Herman et al, 2005). Lesions encompassing the CeA can inhibit HPA-axis responses to at least some forms of stress (Beaulieu et al, 1986; Van de Kar et al, 1991), whereas amygdala stimulation can increase 

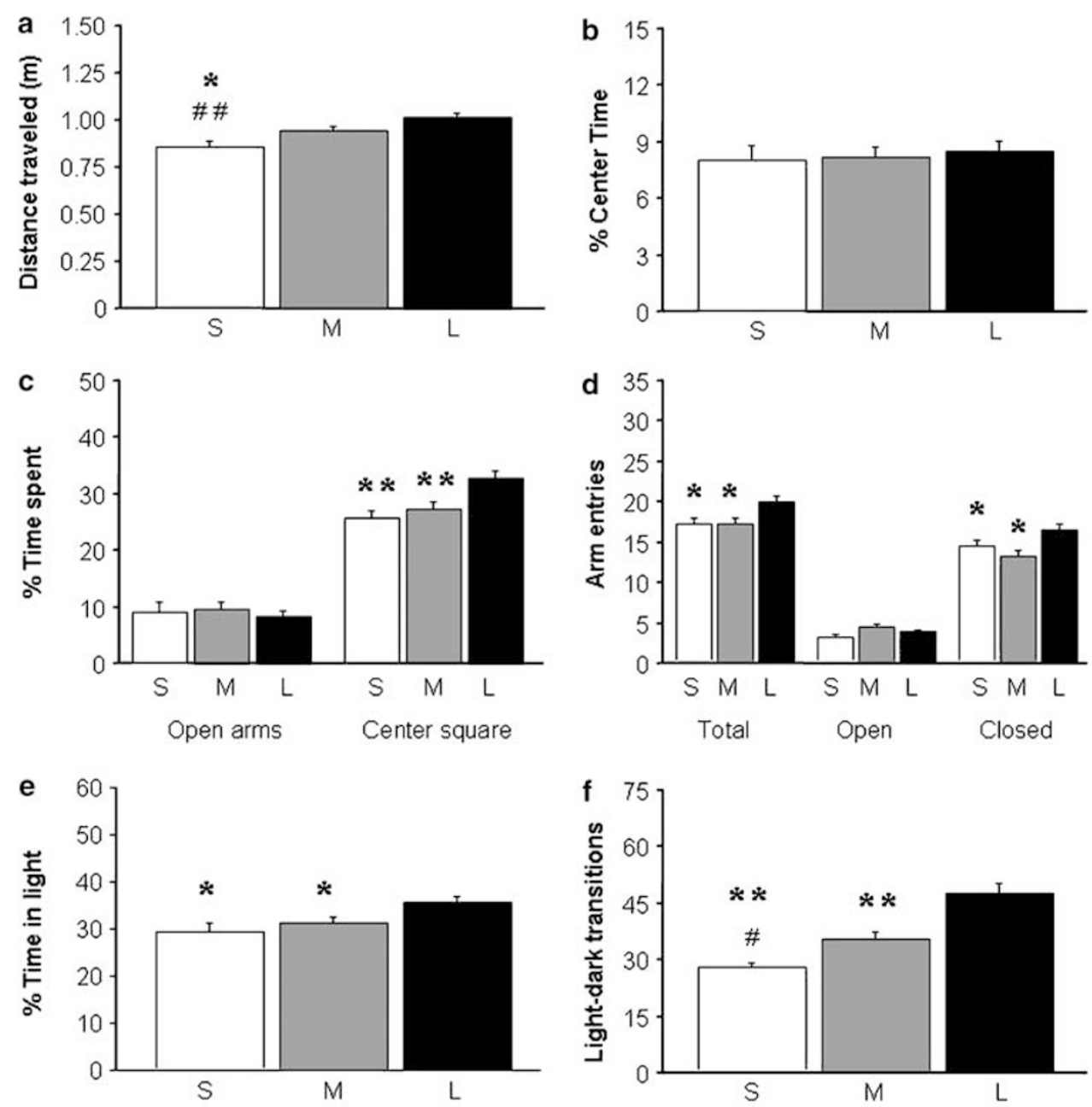

Figure 4 Exploratory- and anxiety-like behaviors in mice differing in basolateral amygdala (BLA) volume. Mice with relatively small (S) BLA traveled less distance than mice with medium (M) or large (L) BLA (a) while groups showed equivalent percent center time (b). Small and medium BLA groups spent less time in the center square but not open arms (c) and made fewer total and closed but not open arm entries (d) in the elevated plus-maze than the large BLA group. Small and medium BLA groups spent less time in the light compartment (e) and made fewer light-dark transitions (f) in the light-dark exploration test than the large BLA group ( $n=35-84$ per volume group). ${ }^{*} * P<0.01$, ${ }^{*} P<.05 \mathrm{vs} L,{ }^{\# \#} P<0.0$ I, ${ }^{\#} P<0.05$ vs $M$.

glucocorticoid release (Redgate and Fahringer, 1973; Dunn and Whitener, 1986). As such, the relatively greater HPA-axis response in small BLA mice could be another manifestation of abnormal amygdala function. Corticosterone also exerts effects within the amygdala via actions at glucocorticoid receptors (Aronsson et al, 1988). Of particular interest in this context, BLA has been identified as a critical site of action through which glucocorticoids modulate associative fear memory, (for example) glucocorticoid receptor agonists administered systemically or directly into the BLA enhance fear conditioning in rats (Zorawski and Killcross, 2002; Hui et al, 2004; Roozendaal et al, 2006). This raises the possibility that increased glucocorticoid receptor activity in smaller BLA mice may be a factor driving enhanced fear conditioning, although this remains to be tested. A related issue is whether BLA variation is a consequence rather than cause of differences in stress reactivity. While we do not discount this possibility it seems unlikely given evidence that chronic stress increases rather than decreases spine density and dendritic arborization in rats and mice (Vyas et al, 2002; Mitra et al, 2005; Govindarajan et al, 2006). On the other hand, because stress causes dendritic shrinkage in rodent ventromedial prefrontal cortex (vmPFC) (Wellman, 2001; Izquierdo et al, 2006; Radley et al, 2006), it would be of interest to examine vmPFC and fear-related behaviors mediated by vmPFC such as fear extinction (Quirk and Mueller, 2007) in mice with different BLA volumes.

BLA groups were selected for differences in BLA volume; and the fact that groups comprised multiple RI strains, each with a unique genotype, reduces the likelihood that differences in fear conditioning and stress reactivity were due to spurious idiosyncrasies (for example poor vision, hearing, nociception) of specific strains. However, this approach cannot exclude the potential contribution of other phenotypic traits that covary with BLA volume. We have recently shown that a common genetic locus may underlie the structures of multiple forebrain regions including amygdala, cerebellum, dorsal striatum, and portions of the hippocampus (Mozhui et al, 2007). Analysis of the volume of these three structures in our three BLA volume groups indicated volume differences in dorsal striatal but not hippocampal or cerebellar volume, raising the possibility that striatal volume variation contributed to behavioral 
differences between BLA groups, (for example via affects on motor function. Arguing against this possibility, however, there were no significant correlations between striatal volume and any behavioral measure (c.f. baseline corticosterone), while BLA volume significantly correlated with novel open-field locomotion. Moreover, BLA volume predicted corticosterone responses to stress, unlikely to be influenced by locomotion, while other measures predicted to be affected by locomotor differences, such as FST immobility, were unrelated to BLA volume. Nonetheless, although present data suggest a specific influence of amygdala function on fear conditioning and stress reactivity, we cannot rule out the possible contribution of differences in other brain regions or other, as yet undetermined, traits genetically correlated with BLA volume. In fact, given the highly integrated nature of the neural circuitry subserving stress, fear, and anxiety behaviors (Amat et al, 2005; Hariri and Holmes, 2006; Quirk and Mueller, 2007; Ressler and Mayberg, 2007; Wellman et al, 2007), it is unlikely that the amygdala would act in isolation to mediate these complex functions.

The finding that relatively smaller BLA is associated with increased fear and stress reactivity may at first appear counterintuitive given the effects of amygdala lesions, but this is in fact entirely consonant with recent findings from genetic studies in humans. For example, functional neuroimaging studies of two gene variants implicated in stress-related disorders, the low-expressing forms of the serotonin transporter and monoamine oxidase A, demonstrate that these variants produce exaggerated amygdala reactivity during fear processing and that this is coupled with lesser amygdala volume (Pezawas et al, 2005; MeyerLindenberg et al, 2006). The volume differences underlying these fear-related phenotypes were modest, as they were in our mouse sample. Thus, it appears that relatively modest variation in BLA volume is sufficient to determine fear- and stress-related phenotypes.

Elucidating the molecular and physiological factors associated with volume differences is likely to be key to understanding this relationship between BLA volume and behavior. A pertinent observation in this regard is that the total number of neurons (and non-neuronal cells) in BLA was equivalent across BLA volume groups (Mozhui et al, 2007), indicating that rather than having a relative loss of neurons, the smaller BLA mice had a slightly denser packing of neurons (see Figure 4d in Mozhui et al, 2007). An important question for future studies will be how variation in this and other intrinsic properties of BLA, such as neuronal morphology and the ratio of excitatory over inhibitory cells, might contribute to the behavioral differences between BLA volume groups. Another interesting question is whether phenotypic differences between BLA groups are localized to specific subnuclei within the BLA complex. For example, akin to the small BLA phenotype observed in our study, lesions of the lateral nucleus prior to fear conditioning block acquisition (Goosens and Maren, 2001; Nader et al, 2001; Koo et al, 2004), postconditioning lesions of the basal nucleus (corresponding to basolateral nucleus in Figure 1a) impair the expression, but not acquisition, of fear memory (Anglada-Figueroa and Quirk, 2005).

In summary, the present study has shown that variation in BLA volume is associated with differences in fear memory, glucocorticoid responses to stress, and locomotor inhibition in response to novelty. The present findings also provide parallels with clinical data, to the extent that PTSD patients also exhibit enhanced fear memory (American Psychiatric Association, 1994; Peri et al, 2000) and exaggerated glucocorticoid responses to stress (Yehuda, 2002; de Kloet et al, 2006), as well as amygdala hyperactivity and possibly smaller amygdala volume (Bremner et al, 1997; Wignall et al, 2004; Karl et al, 2006; Rauch et al, 2006; Shin et al, 2006), relative to controls. Thus, the present study not only provides a novel extension to the literature linking the amygdala with fear- and stress-related processing with possible implications for understanding amygdala dysfunction in PTSD, but also provides one of the first examples of how structural variation in a specific brain region can successfully predict differences in specific phenotypic traits in the rodent.

\section{ACKNOWLEDGEMENTS}

We thank Dr. Glenn D. Rosen for access to a new striatal volume data set on the BXD strains available in GeneNetwork (BXD Phenotype GNID 10710). This research was supported by the NIAAA (Z01-AA000411) and NIMH (Z01-MH002784) intramural research programs, and by NIDA, NIMH, and NIAAA HPG grant P20-DA 21131, NCRR BIRN grant U24 RR021760 (BIRN), and NIAAA INIA grants U01AA13499 and U24AA13513.

\section{DISCLOSURE/CONFLICT OF INTEREST}

The authors have no competing interests.

\section{REFERENCES}

Airey DC, Lu L, Shou S, Williams RW (2002). Genetic sources of individual differences in the cerebellum. Cerebellum 1: 233-240.

Airey DC, Lu L, Williams RW (2001). Genetic control of the mouse cerebellum: identification of quantitative trait loci modulating size and architecture. J Neurosci 21: 5099-5109.

Amat J, Baratta MV, Paul E, Bland ST, Watkins LR, Maier SF (2005). Medial prefrontal cortex determines how stressor controllability affects behavior and dorsal raphe nucleus. Nat Neurosci 8: 365-371.

American Psychiatric Association 1994. Diagnostic and Statistical Manual of Mental Disorders IV. American Psychiatric Press: Washington, DC.

Anglada-Figueroa D, Quirk GJ (2005). Lesions of the basal amygdala block expression of conditioned fear but not extinction. J Neurosci 25: 9680-9685.

Aronsson M, Fuxe K, Dong Y, Agnati LF, Okret S, Gustafsson JA (1988). Localization of glucocorticoid receptor mRNA in the male rat brain by in situ hybridization. Proc Natl Acad Sci USA 85: 9331-9335.

Beaulieu S, Di Paolo T, Barden N (1986). Control of ACTH secretion by the central nucleus of the amygdala: implication of the serotoninergic system and its relevance to the glucocorticoid delayed negative feedback mechanism. Neuroendocrinology 44: 247-254.

Bonne O, Brandes D, Gilboa A, Gomori JM, Shenton ME, Pitman RK et al (2001). Longitudinal MRI study of hippocampal volume in trauma survivors with PTSD. Am J Psychiatry 158: 1248-1251. 
Boyce-Rustay JM, Cameron HA, Holmes A (2007). Chronic swim stress alters sensitivity to acute behavioral effects of ethanol in mice. Physiol Behav 91: 77-86.

Boyce-Rustay JM, Holmes A (2006). Genetic inactivation of the NMDA receptor NR2A subunit has anxiolytic- and antidepressant-like effects in mice. Neuropsychopharmacology 31: 2405-2414.

Bremner JD, Randall P, Vermetten E, Staib L, Bronen RA, Mazure $C$ et al (1997). Magnetic resonance imaging-based measurement of hippocampal volume in posttraumatic stress disorder related to childhood physical and sexual abuse - a preliminary report. Biol Psychiatry 41: 23-32.

Caldarone B, Saavedra C, Tartaglia K, Wehner JM, Dudek BC, Flaherty L (1997). Quantitative trait loci analysis affecting contextual conditioning in mice. Nat Genet 17: 335-337.

Caspi A, Moffitt TE (2006). Gene-environment interactions in psychiatry: joining forces with neuroscience. Nat Rev Neurosci 7: 583-590.

Chesler EJ, Wang J, Lu L, Qu Y, Manly KF, Williams RW (2003). Genetic correlates of gene expression in recombinant inbred strains: a relational model system to explore neurobehavioral phenotypes. Neuroinformatics 1: 343-357.

Crawley JN (1981). Neuropharmacologic specificity of a simple animal model for the behavioral actions of benzodiazepines. Pharmacol Biochem Behav 15: 695-699.

Davis M, Whalen PJ (2001). The amygdala: vigilance and emotion. Mol Psychiatry 6: 13-34.

De Bellis MD, Hall J, Boring AM, Frustaci K, Moritz G (2001). A pilot longitudinal study of hippocampal volumes in pediatric maltreatment-related posttraumatic stress disorder. Biol Psychiatry 50: 305-309.

De Bellis MD, Keshavan MS, Shifflett H, Iyengar S, Beers SR, Hall J et al (2002). Brain structures in pediatric maltreatment-related posttraumatic stress disorder: a sociodemographically matched study. Biol Psychiatry 52: 1066-1078.

de Kloet CS, Vermetten E, Geuze E, Kavelaars A, Heijnen CJ, Westenberg HG (2006). Assessment of HPA-axis function in posttraumatic stress disorder: pharmacological and nonpharmacological challenge tests, a review. J Psychiatr Res 40: 550-567.

Decker MW, Curzon P, Brioni JD (1995). Influence of separate and combined septal and amygdala lesions on memory, acoustic startle, anxiety, and locomotor activity in rats. Neurobiol Learn Mem 64: 156-168.

Dunn JD, Whitener J (1986). Plasma corticosterone responses to electrical stimulation of the amygdaloid complex: cytoarchitectural specificity. Neuroendocrinology 42: 211-217.

Fanselow MS, LeDoux JE (1999). Why we think plasticity underlying Pavlovian fear conditioning occurs in the basolateral amygdala. Neuron 23: 229-232.

Fanselow MS, Poulos AM (2005). The neuroscience of mammalian associative learning. Annu Rev Psychol 56: 207-234.

Fennema-Notestine C, Stein MB, Kennedy CM, Archibald SL, Jernigan TL (2002). Brain morphometry in female victims of intimate partner violence with and without posttraumatic stress disorder. Biol Psychiatry 52: 1089-1101.

Gilbertson MW, Shenton ME, Ciszewski A, Kasai K, Lasko NB, Orr SP et al (2002). Smaller hippocampal volume predicts pathologic vulnerability to psychological trauma. Nat Neurosci 5: 1242-1247.

Goosens KA, Maren S (2001). Contextual and auditory fear conditioning are mediated by the lateral, basal, and central amygdaloid nuclei in rats. Learn Mem 8: 148-155.

Govindarajan A, Rao BS, Nair D, Trinh M, Mawjee N, Tonegawa S et al (2006). Transgenic brain-derived neurotrophic factor expression causes both anxiogenic and antidepressant effects. Proc Natl Acad Sci USA 103: 13208-13213.

Gurvits TV, Metzger LJ, Lasko NB, Cannistraro PA, Tarhan AS, Gilbertson MW et al (2006). Subtle neurologic compromise as a vulnerability factor for combat-related posttraumatic stress disorder: results of a twin study. Arch Gen Psychiatry 63: 571-576.

Handley SL, Mithani S (1984). Effects of alpha-adrenoceptor agonists and antagonists in a maze-exploration model of 'fear'-motivated behaviour. Naunyn Schmiedebergs Arch Pharmacol 327: 1-5.

Hariri AR, Drabant EM, Weinberger DR (2006). Imaging genetics: perspectives from studies of genetically driven variation in serotonin function and corticolimbic affective processing. Biol Psychiatry 59: 888-897.

Hariri AR, Holmes A (2006). Genetics of emotional regulation: the role of the serotonin transporter in neural function. Trends Cogn Sci 10: $182-191$.

Hefner K, Holmes A (2007). Ontogeny of fear-, anxiety- and depression-related behavior across adolescence in C57BL/6J mice. Behav Brain Res 176: 210-215.

Herman JP, Ostrander MM, Mueller NK, Figueiredo H (2005). Limbic system mechanisms of stress regulation: hypothalamopituitary-adrenocortical axis. Prog Neuropsychopharmacol Biol Psychiatry 29: 1201-1213.

Herry C, Bach DR, Esposito F, Di Salle F, Perrig WJ, Scheffler K et al (2007). Processing of temporal unpredictability in human and animal amygdala. J Neurosci 27: 5958-5966.

Holmes A, Kinney JW, Wrenn CC, Li Q, Yang RJ, Ma L et al (2003). Galanin GAL-R1 receptor null mutant mice display increased anxiety-like behavior specific to the elevated plus-maze. Neuropsychopharmacology 28: 1031-1044.

Hui GK, Figueroa IR, Poytress BS, Roozendaal B, McGaugh JL, Weinberger NM (2004). Memory enhancement of classical fear conditioning by post-training injections of corticosterone in rats. Neurobiol Learn Mem 81: 67-74.

Izquierdo A, Wellman CL, Holmes A (2006). Brief uncontrollable stress causes dendritic retraction in infralimbic cortex and resistance to fear extinction in mice. J Neurosci 26: 5733-5738.

Karl A, Schaefer M, Malta LS, Dorfel D, Rohleder N, Werner A (2006). A meta-analysis of structural brain abnormalities in PTSD. Neurosci Biobehav Rev 30: 1004-1031.

Kendler KS (2001). Twin studies of psychiatric illness: an update. Arch Gen Psychiatry 58: 1005-1014.

Kim JJ, Fanselow MS (1992). Modality-specific retrograde amnesia of fear. Science 256: 675-677.

Kliethermes CL, Crabbe JC (2006). Genetic independence of mouse measures of some aspects of novelty seeking. Proc Natl Acad Sci USA 103: 5018-5023.

Koo JW, Han JS, Kim JJ (2004). Selective neurotoxic lesions of basolateral and central nuclei of the amygdala produce differential effects on fear conditioning. J Neurosci 24: 7654-7662.

Lin CH, Hansen S, Wang Z, Storm DR, Tapscott SJ, Olson JM (2005). The dosage of the neuroD2 transcription factor regulates amygdala development and emotional learning. Proc Natl Acad Sci USA 102: 14877-14882.

Lindauer RJ, Vlieger EJ, Jalink M, Olff M, Carlier IV, Majoie CB et al (2004). Smaller hippocampal volume in Dutch police officers with posttraumatic stress disorder. Biol Psychiatry 56: 356-363.

Lu L, Airey DC, Williams RW (2001). Complex trait analysis of the hippocampus: mapping and biometric analysis of two novel gene loci with specific effects on hippocampal structure in mice. J Neurosci 21: 3503-3514.

Maren S, Quirk GJ (2004). Neuronal signalling of fear memory. Nat Rev Neurosci 5: 844-852.

Meyer-Lindenberg A, Buckholtz JW, Kolachana B, A RH, Pezawas $\mathrm{L}$, Blasi $\mathrm{G}$ et al (2006). Neural mechanisms of genetic risk for impulsivity and violence in humans. Proc Natl Acad Sci USA 103: 6269-6274.

Mitra R, Jadhav S, McEwen BS, Vyas A, Chattarji S (2005). Stress duration modulates the spatiotemporal patterns of spine formation in the basolateral amygdala. Proc Natl Acad Sci USA 102: 9371-9376. 
Moller C, Wiklund L, Sommer W, Thorsell A, Heilig M (1997). Decreased experimental anxiety and voluntary ethanol consumption in rats following central but not basolateral amygdala lesions. Brain Res 760: 94-101.

Moreira CM, Masson S, Carvalho MC, Brandao ML (2007). Exploratory behaviour of rats in the elevated plus-maze is differentially sensitive to inactivation of the basolateral and central amygdaloid nuclei. Brain Res Bull 71: 466-474.

Mozhui K, Hamre KM, Holmes A, Lu L, Williams RW (2007). Genetic and structural analysis of the basolateral amygdala complex in BXD recombinant inbred mice. Behav Genet 37: 223-243.

Nader K, Majidishad P, Amorapanth P, LeDoux JE (2001). Damage to the lateral and central, but not other, amygdaloid nuclei prevents the acquisition of auditory fear conditioning. Learn Mem 8: 156-163.

Neumann PE, Garretson JD, Skabardonis GP, Mueller GG (1993). Genetic analysis of cerebellar folial pattern in crosses of C57BL/ 6J and DBA/2J inbred mice. Brain Res 619: 81-88.

Owen EH, Christensen SC, Paylor R, Wehner JM (1997). Identification of quantitative trait loci involved in contextual and auditory-cued fear conditioning in BXD recombinant inbred strains. Behav Neurosci 111: 292-300.

Peirce JL, Chesler EJ, Williams RW, Lu L (2003). Genetic architecture of the mouse hippocampus: identification of gene loci with selective regional effects. Genes Brain Behav 2: 238-252.

Peri T, Ben-Shakhar G, Orr SP, Shalev AY (2000). Psychophysiologic assessment of aversive conditioning in posttraumatic stress disorder. Biol Psychiatry 47: 512-519.

Pezawas L, Meyer-Lindenberg A, Drabant EM, Verchinski BA, Munoz KE, Kolachana BS et al (2005). 5-HTTLPR polymorphism impacts human cingulate-amygdala interactions: a genetic susceptibility mechanism for depression. Nat Neurosci 8: 828-834.

Phelps EA, LeDoux JE (2005). Contributions of the amygdala to emotion processing: from animal models to human behavior. Neuron 48: 175-187.

Porsolt RD, Bertin A, Jalfre M (1978). 'Behavioural despair' in rats and mice: strain differences and the effects of imipramine. Eur J Pharmacol 51: 291-294.

Quirk GJ, Mueller D (2007). Neural mechanisms of extinction learning and retrieval. Neuropsychopharmacology 33: 56-72.

Radley JJ, Rocher AB, Miller M, Janssen WG, Liston C, Hof PR et al (2006). Repeated stress induces dendritic spine loss in the rat medial prefrontal cortex. Cereb Cortex 16: 313-320.

Rauch SL, Shin LM, Phelps EA (2006). Neurocircuitry models of posttraumatic stress disorder and extinction: human neuroimaging research - past, present, and future. Biol Psychiatry 60: 376-382.

Redgate ES, Fahringer EE (1973). A comparison of the pituitary adrenal activity elicited by electrical stimulation of preoptic, amygdaloid and hypothalamic sites in the rat brain. Neuroendocrinology 12: 334-343.

Ressler KJ, Mayberg HS (2007). Targeting abnormal neural circuits in mood and anxiety disorders: from the laboratory to the clinic. Nat Neurosci 10: 1116-1124.

Robbins TW, Everitt BJ (2002). Limbic-striatal memory systems and drug addiction. Neurobiol Learn Mem 78: 625-636.

Roozendaal B, Hui GK, Hui IR, Berlau DJ, McGaugh JL, Weinberger NM (2006). Basolateral amygdala noradrenergic activity mediates corticosterone-induced enhancement of auditory fear conditioning. Neurobiol Learn Mem 86: 249-255.

Rosen GD, Williams RW (2001). Complex trait analysis of the mouse striatum: independent QTLs modulate volume and neuron number. BMC Neurosci 2: 5.

Seecharan DJ, Kulkarni AL, Lu L, Rosen GD, Williams RW (2003). Genetic control of interconnected neuronal populations in the mouse primary visual system. J Neurosci 23: 11178-11188.
Shimazoe T, Shibata S, Yatsugi S, Ueki S (1988). Involvement of the medial amygdaloid nucleus in the action of imipramine in rats subjected to the forced swimming test. J Pharmacobiodyn 11: 137-139.

Shin LM, Rauch SL, Pitman RK (2006). Amygdala, medial prefrontal cortex, and hippocampal function in PTSD. Ann NY Acad Sci 1071: 67-79.

Swanson LW, Petrovich GD (1998). What is the amygdala? Trends Neurosci 21: 323-331.

Taylor BA (1978). Recombinant inbred strains: use in gene mapping. In: Morse HC (ed). Origins of Inbred Mice. Academic Press: New York. pp 423-438.

Turri MG, Talbot CJ, Radcliffe RA, Wehner JM, Flint J (1999). High-resolution mapping of quantitative trait loci for emotionality in selected strains of mice. Mamm Genome 10: 1098-1101.

Valentinuzzi VS, Kolker DE, Vitaterna MH, Shimomura K, Whiteley A, Low-Zeddies S et al (1998). Automated measurement of mouse freezing behavior and its use for quantitative trait locus analysis of contextual fear conditioning in (BALB/ cJ $\times$ C57BL/6J)F2 mice. Learn Mem 5: 391-403.

Van de Kar LD, Piechowski RA, Rittenhouse PA, Gray TS (1991). Amygdaloid lesions: differential effect on conditioned stress and immobilization-induced increases in corticosterone and renin secretion. Neuroendocrinology 54: 89-95.

Vyas A, Mitra R, Shankaranarayana Rao BS, Chattarji S (2002). Chronic stress induces contrasting patterns of dendritic remodeling in hippocampal and amygdaloid neurons. J Neurosci 22: $6810-6818$.

Wahlsten D, Bachmanov A, Finn DA, Crabbe JC (2006). Stability of inbred mouse strain differences in behavior and brain size between laboratories and across decades. Proc Natl Acad Sci USA 103: $16364-16369$.

Wehner JM, Radcliffe RA, Rosmann ST, Christensen SC, Rasmussen DL, Fulker DW et al (1997). Quantitative trait locus analysis of contextual fear conditioning in mice. Nat Genet 17: 331-334.

Wellman CL (2001). Dendritic reorganization in pyramidal neurons in medial prefrontal cortex after chronic corticosterone administration. J Neurobiol 49: 245-253.

Wellman CL, Izquierdo A, Garret JE, Martin KP, Carroll J, Millstein $\mathrm{R}$ et al (2007). Impaired stress-coping and fear extinction and abnormal corticolimbic morphology in serotonin transporter knock-out mice. J Neurosci 27: 684-691.

Wiedholz LM, Owens WA, Horton RE, Feyder M, Karlsson RM, Hefner K et al (2007). Mice lacking the AMPA GluR1 receptor exhibit striatal hyperdopaminergia and 'schizophrenia-related' behaviors. Mol Psychiatry.

Wignall EL, Dickson JM, Vaughan P, Farrow TF, Wilkinson ID, Hunter MD et al (2004). Smaller hippocampal volume in patients with recent-onset posttraumatic stress disorder. Biol Psychiatry 56: $832-836$.

Williams RW (2000). Mapping genes that modulate mouse brain development: a quantitative genetic approach. Results Probl Cell Differ 30: 21-49.

Williams RW, Airey DC, Kulkarni A, Zhou G, Lu L (2001). Genetic dissection of the olfactory bulbs of mice: QTLs on four chromosomes modulate bulb size. Behav Genet 31: 61-77.

Yehuda R (2002). Current status of cortisol findings in post-traumatic stress disorder. Psychiatr Clin North Am 25: 341-368.

Zorawski M, Killcross S (2002). Posttraining glucocorticoid receptor agonist enhances memory in appetitive and aversive Pavlovian discrete-cue conditioning paradigms. Neurobiol Learn Mem 78: 458-464. 